\title{
Comparison of temperature measurements in esophagus and urinary bladder in comatose patients after cardiac arrest undergoing mild therapeutic hypothermia
}

\author{
Julia M. Umińska ${ }^{1}$, Katarzyna Buszko ${ }^{1}$, Jakub Ratajczak ${ }^{1}$, Piotr Łach $^{1}$, \\ Krzysztof Pstragowski ${ }^{1}$, Anita Dąbrowska ${ }^{1}$, Piotr Adamski ${ }^{1}$, \\ Grzegorz Skonieczny ${ }^{2}$, Jacek Manitius ${ }^{1}$, Jacek Kubica ${ }^{1}$ \\ ${ }^{1}$ Collegium Medicum, Nicolaus Copernicus University, Bydgoszcz, Poland \\ ${ }^{2}$ Ludwik Rydygier Voivodship Polyclinical Hospital, Torun, Poland
}

\begin{abstract}
Background: Mild therapeutic hypothermia (MTH) is a recommended method of treatment for comatose out-of-hospital cardiac arrest (OHCA) survivors. However, the proper site of temperature measurement in MTH is still not defined. The aim of this study was to compare temperature measurements in the esophagus and urinary bladder in comatose post-OHCA patients treated with MTH.

Methods: This temperature comparison protocol was a part of a prospective, observational, multicenter cohort study. The study population included 36 unconscious patients after resuscitation for OHCA. The patient's core temperature was independently measured every hour during MTH in the urinary bladder and in the esophagus.

Results: The mean temperature was lower in the esophagus (differences during induction phase: $1.04 \pm 0.92^{\circ} \mathrm{C}, p<0.0001$; stabilization phase: $0.54 \pm 0.39^{\circ} \mathrm{C}, p<0.0001$; rewarming phase: $\left.0.40 \pm 0.47^{\circ} \mathrm{C}, p<0.0001\right)$. Nevertheless, a strong correlation between both sites was found $\left(R^{2}=0.83\right.$, $p<0.001)$. The decrease in temperature observed in the esophagus during the induction phase was faster when compared with the urinary bladder $\left(1.09 \pm 0.71^{\circ} \mathrm{C} / \mathrm{h}\right.$ vs. $\left.0.83 \pm 0.41^{\circ} \mathrm{C} / \mathrm{h} ; p=0.002\right)$. As a consequence, time to reach temperature $<34.0^{\circ} \mathrm{C}$ was longer when temperature was measured in the urinary bladder (the difference between medians of the time 1.0 [0-1.5] $h, p<0.001$ ).

Conclusions: Urinary bladder temperature measurements may lag behind temperature changes measured in the esophagus. Monitoring temperature simultaneously in the esophagus and in the urinary bladder is an accessible and reliable combination, although esophageal measurements seem to better reflect the dynamics of temperature changes, thus it seems to be more appropriate for MTH control. ClinicalTrials.gov Identifier: NCT02611934 (Cardiol J 2020; 27, 6: 735-741)
\end{abstract}

Key words: cardiac arrest, mild therapeutic hypothermia, temperature measurement

\section{Introduction}

Several relatively small randomized studies involving unconscious cardiac arrest survivors showed a significant improvement in neurologic function and survival rate with mild therapeutic hypothermia (MTH) of a target temperature between $32^{\circ} \mathrm{C}$ and $34^{\circ} \mathrm{C}$ [1-3]. A favorable effect of MTH on survival and neurological outcome was confirmed in meta-analysis pooling data from non-randomized studies [4]. However, results of the largest available randomized trial published

Address for correspondence: Julia M. Umińska, MD, Department of Cardiology and Internal Medicine, Collegium Medicum, Nicolaus Copernicus University, ul. M. Skłodowskiej-Curie 9, 85-094 Bydgoszcz, Poland, tel: +48 525854023 , fax: +485258549 4024, e-mail: julia@uminska.net 
by Nielsen et al. [5] did not show superiority of MTH at the targeted temperature of $33^{\circ} \mathrm{C}$ above fever prevention at a targeted temperature of $36^{\circ} \mathrm{C}$. Therefore, in the current European Society of Cardiology (ESC) guidelines for both strategies are proposed as equivalent for comatose cardiac arrest survivors [6].

Regardless of the target temperature, an accurate temperature control during MTH is required [7]. Measurement of central circulation temperature or brain tissue temperature is difficult to apply in an emergency setting, therefore surrogate sites such as urinary bladder, rectum, tympanic membrane, or esophagus, are often used [8-11]. However, the current guidelines do not define the proper site of temperature measurement for MTH control. It is recommended that patients undergoing hypothermia body core temperature should be measured at two different sites [12], band yet for feedback-controlled devices with endovascular cooling catheters or surface cooling, only one temperature measurement site for automatic guidance of MTH is required [13]. Esophagus and urinary bladder are currently the most commonly used sites.

Based on the available data from studies with a low number of patients enrolled it was hypothesized that the temperature measured in the urinary bladder is not accurate when compared to the esophageal temperature at the induction phase of MTH. As expected herein, lagging of measurements in urinary bladder is behind the core temperature change measured in esophagus.

The aim of this study was to perform a $24-\mathrm{h}$, complete (covering three MTH phases: induction, stabilization and warming) comparison of temperature measurements in the esophagus and urinary bladder in comatose patients after cardiac arrest treated with MTH.

\section{Methods}

\section{Study design}

This temperature comparison protocol was a part of a prospective, observational, multicenter cohort study entitled Mild Therapeutic Hypothermia for Patients with Acute Coronary Syndrome and Cardiac Arrest Treated with Percutaneous Coronary Intervention (the UNICORN trial) [14]. The study was conducted in accordance with the principles contained in the Declaration of Helsinki and Good Clinical Practice guidelines. The study was approved by the Ethics Committee of Nicolaus Copernicus University in Torun, Collegium
Medicum in Bydgoszcz (study approval reference number KB 615/2015).

\section{Study population}

The study population included 36 unconscious patients after resuscitation for out-of-hospital cardiac arrest (OHCA) with shockable rhythm presenting with acute coronary syndrome (ACS). Initially 42 patients were enrolled in the study, however 6 of them were eventually excluded from analysis due to a lack of complete data. Baseline characteristics of study participants are presented in Table 1.

After admission to the study center and confirmation of initial diagnosis, patients were screened for eligibility to the trial. All enrolled subjects were treated with MTH in addition to standard therapy baccording to the previously described protocol [14]. Inclusion criteria were defined as:

- age $\geq 18$ years;

- OHCA survivor;

- sustained return of spontaneous circulation (ROSC) for more than 20 min after resuscitation;

- unconsciousness with a score of $\leq 8$ on the Glasgow Coma Scale after ROSC;

- shockable initial rhythm;

- diagnosis or suspicion of ACS. The exclusion criteria included:

- unwitnessed OHCA;

- obvious or suspected pregnancy;

- known serious infection before OHCA;

- known bleeding diathesis;

- confirmed or suspected internal bleeding;

- confirmed or suspected acute stroke;

- confirmed or suspected cerebral injury;

- known serious neurological dysfunction before OHCA (Cerebral Performance Category $\leq 4$ );

- known serious disease making 180 days of survival unlikely;

- hemodynamic instability with systolic blood pressure $<65 \mathrm{mmHg}$ despite the treatment;

- time delay from ROSC to MTH induction $>240 \mathrm{~min}$;

- asystole or pulseless electrical activity as the initial rhythm [14].

\section{Treatment and temperature measurement}

Mild therapeutic hypothermia was induced and maintained for $24 \mathrm{~h}$ at a target temperature of $33^{\circ} \mathrm{C}$ using Intravascular Temperature Management ${ }^{\mathrm{TM}}$, CoolGard $3000^{\circledR}$ (Zoll Circulation Inc., USA) and a MTH-dedicated catheter (Mon-a-Therm ${ }^{\mathrm{TM}}$ Foley Catheter with Temperature Sensor 400TM, Covidi- 
Table 1. Baseline characteristics of patients.

\begin{tabular}{|c|c|}
\hline Variable & $\begin{array}{l}\text { Patients undergoing } \\
\text { MTH procedure } \\
\text { (n= 36) }\end{array}$ \\
\hline \multicolumn{2}{|l|}{ Demographic characteristics } \\
\hline Age [years] & $62.3 \pm 12.9$ \\
\hline Female & $6(16.7 \%)$ \\
\hline \multicolumn{2}{|l|}{ Medical history } \\
\hline Diabetes mellitus & $13(36.1 \%)$ \\
\hline Arterial hypertension & $17(47.2 \%)$ \\
\hline Prior stroke & $2(5.6 \%)$ \\
\hline Prior myocardial infarction & $11(30.5 \%)$ \\
\hline \multicolumn{2}{|l|}{$\begin{array}{l}\text { Patient status on admission } \\
\text { and in-hospital management }\end{array}$} \\
\hline \multicolumn{2}{|l|}{ GCS on hospital admission: } \\
\hline $3-4$ points & $25(69.5 \%)$ \\
\hline $5-6$ points & $11(30.6 \%)$ \\
\hline $7-8$ points & $0(0.0 \%)$ \\
\hline Shock on hospital admission & $22(61.1 \%)$ \\
\hline LVEF on hospital admission [\%] & $32.6 \pm 8.8$ \\
\hline \multicolumn{2}{|l|}{ Underlying cause of OHCA: } \\
\hline STEMI & $22(61.2 \%)$ \\
\hline NSTEMI & $6(16.7 \%)$ \\
\hline Other & $8(22.2 \%)$ \\
\hline \multicolumn{2}{|l|}{ Presence of CAD: } \\
\hline Single-vessel & $10(27.8 \%)$ \\
\hline Multi-vessel & $20(55.6 \%)$ \\
\hline $\begin{array}{l}\text { Without significant } \\
\text { coronary lesions }\end{array}$ & $6(16.7 \%)$ \\
\hline Treatment with $\mathrm{PCl}$ & $30(83.3 \%)$ \\
\hline Use of IABC & $4(11.1 \%)$ \\
\hline \multicolumn{2}{|l|}{ Patient status on discharge } \\
\hline Survival rate & $24(66.6 \%)$ \\
\hline \multicolumn{2}{|l|}{$\mathrm{CPC}$ at discharge: } \\
\hline 1 & $9(25 \%)$ \\
\hline 2 & $6(16.6 \%)$ \\
\hline 3 & $7(19.4 \%)$ \\
\hline 4 & $2(5.6 \%)$ \\
\hline 5 & $12(33.3 \%)$ \\
\hline
\end{tabular}

Data are presented as mean \pm standard deviation or number (percentages). CAD - coronary artery disease; CPC - Cerebral Performance Category; GCS - Glasgow Coma Score; IABC intra-aortic balloon counterpulsation; LVEF — left ventricular ejection fraction; MTH - mild therapeutic hypothermia; NSTEMI non-ST-segment elevation myocardial infarction; OHCA - out-of-hospital cardiac arrest; $\mathrm{PCl}$ - percutaneous coronary intervention; STEMI - ST-segment elevation myocardial infarction

ent Company, Ireland) introduced into the inferior vena cava through a femoral vein. The induction phase was supported by infusion of cold saline
( $0.9 \%$ solution of sodium chloride at the temperature of $4^{\circ} \mathrm{C}$ ) and use of ice packs. The rewarming phase was conducted in an actively controlled manner $\left(0.3^{\circ} \mathrm{C}\right.$ per hour $)$. The cooling device used urinary bladder temperature as feedback to guide changes in patient temperature.

Each patient's core temperature was independently measured every hour during the MTH procedure (including induction of hypothermia and rewarming phase) in the urinary bladder and in the lower one third of the esophagus using a dedicated monitor (Monitor Philips IntelliVue MP-60, temperature module M1029A, Philips Medical Systems, UK) and catheter (ER 400-9 Level ${ }^{\circledast}$ Esophageal Temperature Probe Thermistor, Smiths Medical ASD Inc., USA). Before every clinical application both probes were calibrated exvivo and checked for measurement concordance.

All patients were mechanically ventilated with a concomitant continuous intravenous infusion of propofol and fentanyl for sedation and analgesia, and treated according to current ESC guidelines.

\section{Sample size calculation}

Based on a sample size calculation and data published by Lefrant et al. [15] and assuming a two-sided alpha value of 0.05 , it was calculated that enrolment of 18 patients would provide a $95 \%$ power to detect significant differences between temperatures measured in the urinary bladder and the esophagus. To provide more reliable data, it was decided to double the minimum number of patients to be enrolled $(n=36)$.

\section{Statistical analysis}

Statistical calculations were performed using the Statistica 12.5 package (StatSoft, Tulsa, OK, USA). Due to the absence of normal distribution of data (as assessed by the Shapiro-Wilk test) all analyses were performed using nonparametric tests. The differences between paired medians were compared with the Wilcoxon signed rank test. The differences between medians together with lower and upper quartiles were quoted. In all cases, two-sided p-values $<0.05$ were considered significant.

\section{Results}

The temperature was measured in all patients every hour during three phases of MTH (induction, stabilization and rewarming). In total 3286 temperature measurements were analyzed (1643 for each site - esophagus and urinary bladder). 
The mean temperature measured in the esophagus was lower when compared with temperature in the urinary bladder during all three phases of MTH procedure (Figs. 1, 2). The greatest difference in temperature assessed at these sites was observed during the induction phase (difference of $\left.1.04 \pm 0.92^{\circ} \mathrm{C}, \mathrm{p}<0.0001\right)$. Temperature differences between measurement sites at stabilization and rewarming phases were smaller than during induction, however these differences were also statistically significant (stabilization: difference of $0.54 \pm 0.39^{\circ} \mathrm{C}, \mathrm{p}<0.0001$; rewarming: difference of $\left.0.40 \pm 0.47^{\circ} \mathrm{C}, \mathrm{p}<0.0001\right)$. Nevertheless, a strong correlation between temperature measurement sites was found $\left(\mathrm{R}^{2}=0.8348, \mathrm{p}<0.001\right)$.

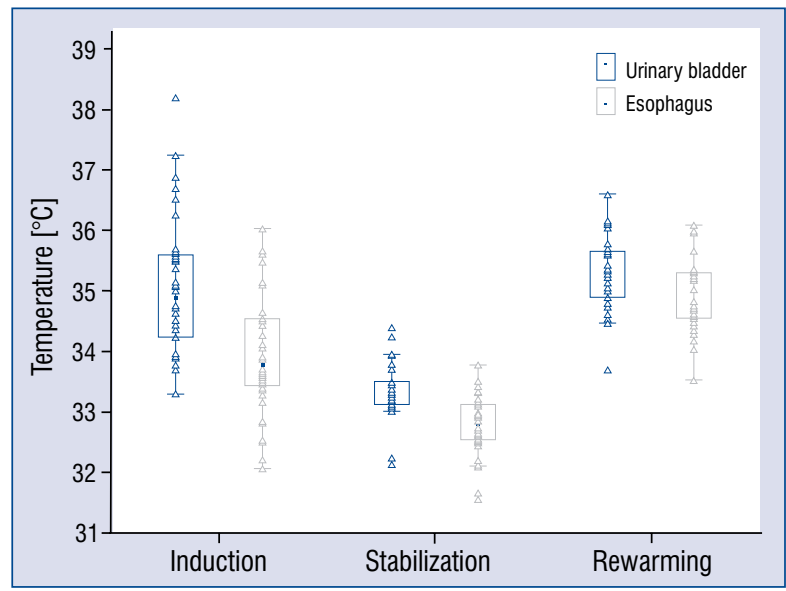

Figure 1. Mean temperatures at the induction, stabilization and rewarming phase of mild therapeutic hypothermia.
The temperature measured in the esophagus decreased faster than in the urinary bladder during the induction phase $\left(1.09 \pm 0.71^{\circ} \mathrm{C} / \mathrm{h}\right.$ vs. $0.83 \pm$ $\left.\pm 0.41^{\circ} \mathrm{C} / \mathrm{h} ; \mathrm{p}=0.002\right)$. As a consequence, time to reach hypothermia $\left(<34.0^{\circ} \mathrm{C}\right)$ was longer when temperature was measured in the urinary bladder than in the esophagus. The difference between medians of time to the target temperature at each site was $1.0(0.5-1.5)$ hour with $\mathrm{p}<0.001$.

During the second phase of MTH, well managed temperature stabilization was reached. The vast majority of measurements, regardless of measurement site, remained within target limits $\left(32-34^{\circ} \mathrm{C}\right)$ (Figs. 1, 2).

Temporary velocities of temperature changes were greatest during the induction phase, smaller in the rewarming phase, while in the stabilization phase they remained close to zero.

The Bland-Altman plot of temperatures measured in the esophagus vs. temperatures measured in the urinary bladder confirmed substantial differences between both methods (Fig. 3).

\section{Discussion}

Although temperature of blood perfusing the hypothalamus is a reference of core body temperature, pulmonary artery temperature is considered the gold standard in critical care, because it has been shown to be closest to the temperature in the high internal jugular vein and core body temperature [16]. Nevertheless, pulmonary artery catheterization is not routinely performed in intensive care patients. When evaluating possible surrogates for pulmonary artery temperature, it

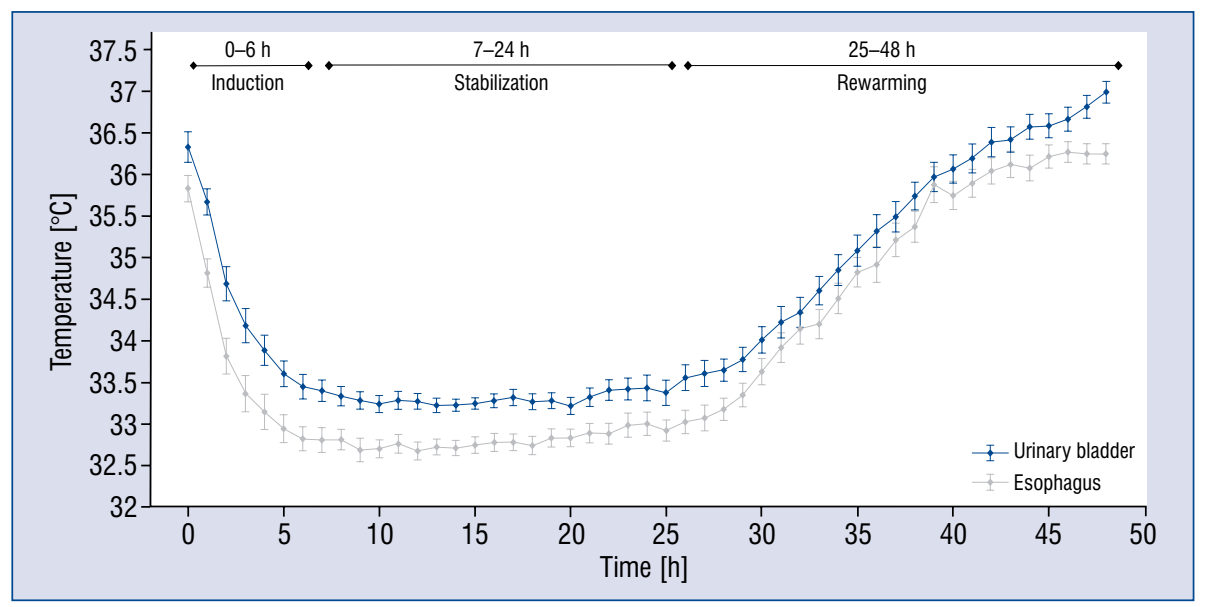

Figure 2. Temperatures measured in the esophagus and urinary bladder in patients undergoing mild therapeutic hypothermia. 


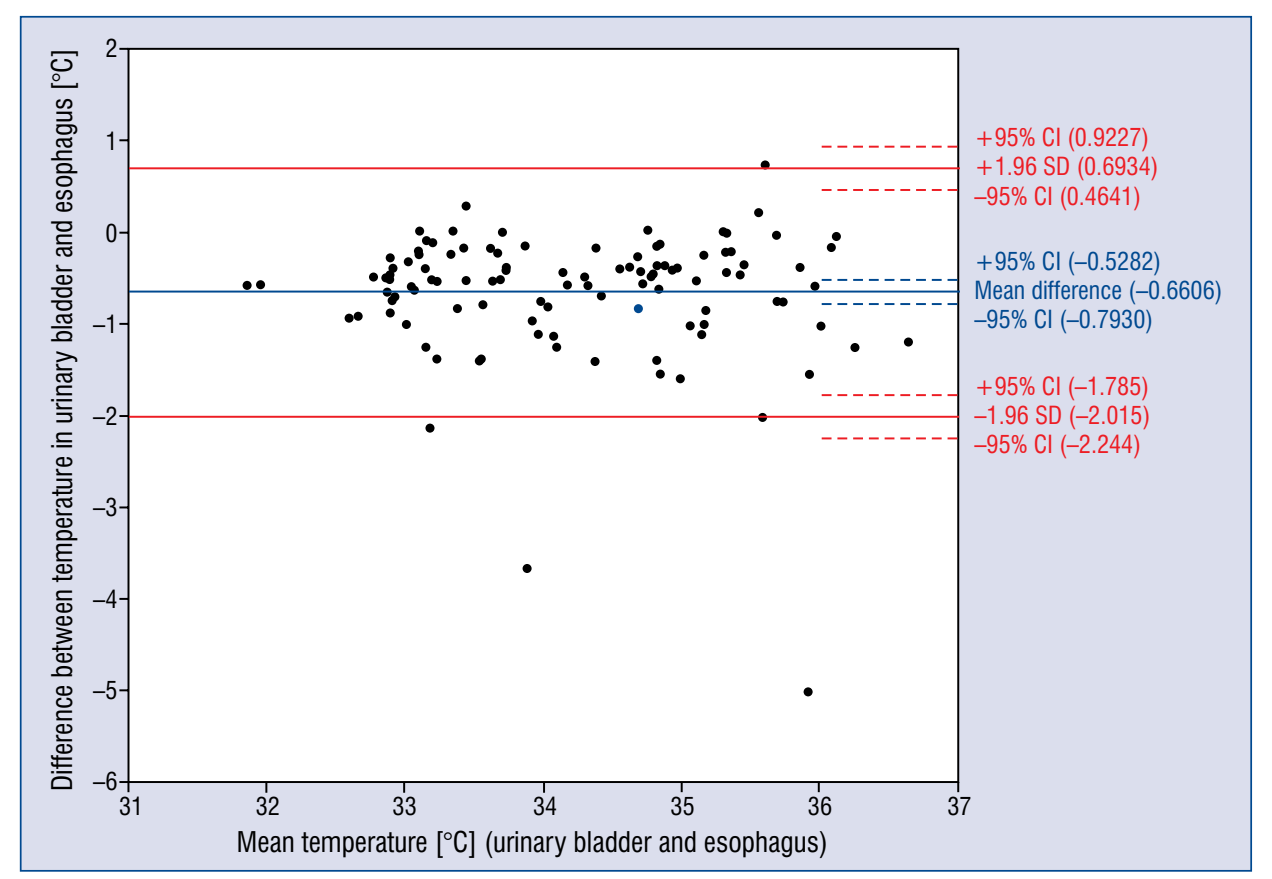

Figure 3. Bland-Altman Plot analysis of temperature difference as measured in the esophagus and urinary bladder; $\mathrm{Cl}$ - confidence interval; SD — standard deviation.

was generally agreed that it would be desirable to have an accurate, easy-to-use monitoring. Yet, from a literature review it was evident that there is still much conflicting data regarding the best surrogate for measuring core temperature [11, 12, 16-18].

The main findings of this study were significant differences in temperature measurements performed in the esophagus and urinary bladder during MTH procedure. The temperature in the esophagus was lower during hypothermia with the greatest differences observed during the induction phase. As a result, time to reach the target temperature was approximately $1 \mathrm{~h}$ longer when the temperature was assessed in the urinary bladder compared with the esophagus.

Very few, low subject number and fragmentary studies comparing different methods of temperature monitoring during MTH are available [13, 17, $19,20]$. Some reports suggest that urinary bladder site does not reflect real-time temperature changes when hypothermia is induced, and temperature changes at this location lag behind body core temperature changes $[17,19]$. This observation however, was not confirmed in other studies [15, 20].

Maintenance of the core temperature within $32-34^{\circ} \mathrm{C}$ is one of the most important issues during MTH. Lefrant et al. [15] showed that mean differences in blood temperature in the pulmonary artery vs. esophageal and urinary bladder tem- peratures were $0.11 \pm 0.30^{\circ} \mathrm{C}$ and $-0.21 \pm 0.20^{\circ} \mathrm{C}$, respectively, in patients with temperatures which ranged from $33.7^{\circ} \mathrm{C}$ to $40.2^{\circ} \mathrm{C}$. According to this study, urinary bladder measurement site is preferable because its accuracy reaches $\pm 0.4^{\circ} \mathrm{C}$ in the most critically ill patients, while the esophageal temperature could be an alternative when urinary bladder temperature cannot be used as an esophageal probe can easily be inserted in intubated and sedated patients. However, according to Shin et al. [13] the accuracy of urinary bladder temperature measurement during the induction phase was lower than at maintenance and rewarming phases. Erickson and Kirklin [18] found that when patients were normothermic, bladder temperature was slightly higher than pulmonary artery temperature, but this was reversed when patients became hypothermic.

Data originating from another study suggested that during rapid temperature change in patients undergoing cardiopulmonary bypass in deep hypothermia, nasopharyngeal, esophageal, and pulmonary nartery temperatures corresponded with brain temperature with smaller mean differences than temperatures measured at the tympanic membrane, urinary bladder, rectum, axilla, and sole of the foot [8]. Nevertheless, the differences reported for deep hypothermia may not reflect the situation present in MTH.

Markota et al. [19] compared temperature changes measured in the esophagus and urinary 
bladder in 8 survivors of cardiac arrest at the induction phase of MTH with cold saline infusion. Target temperature was achieved significantly earlier in the esophagus as compared with the urinary blad$\operatorname{der}(33 \pm 15 \mathrm{~min}$ vs. $63 \pm 15 \mathrm{~min} ; \mathrm{p}=0.006)$. The decrease in temperature measured in the esophagus was much faster $\left(3.27 \pm 1.27^{\circ} \mathrm{C} / \mathrm{h}\right.$ vs. $1.6 \pm$ $\pm 0.89^{\circ} \mathrm{C} / \mathrm{h} ; \mathrm{p}=0.008$ ) with the greatest differences after 30-35 $\mathrm{min}$ [19]. On the other hand, a study by Knapik et al. [20] comparing pulmonary artery, nasopharyngeal, and urinary bladder temperatures in 12 OHCA survivors undergoing MTH found no differences between these sites. In that study, however, the induction of hypothermia was much longer (time to target temperature in esophagus was $4.2 \pm 3.6 \mathrm{~h}$ ). The mean cooling rate was $0.89 \pm 0.96^{\circ} \mathrm{C} / \mathrm{h}$. The major limitation of both aforementioned studies was a low number of patients enrolled $[19,20]$. Of note, the rate of temperature decrease observed in urinary bladder in the present study was similar to the rate reported by Markota et al. [19] and by Knapik et al. [20].

According to results obtained by Krizanac et al. [17] in 20 patients undergoing MTH, the temperature difference between pulmonary artery and esophagus was $0.1 \pm 0.1^{\circ} \mathrm{C}$ during the overall procedure of hypothermia and $0.2 \pm 0.2^{\circ} \mathrm{C}$ during the induction phase. The respective differences between pulmonary artery and urinary bladder were $0.1 \pm 0.2^{\circ} \mathrm{C}$ and $0.4 \pm 0.3^{\circ} \mathrm{C}(\mathrm{p}<0.01$ for all differences). These dissimilarities may result in serious differences of cooling duration and actual core temperature magnitude, when different temperature assessment sites are applied [17]. The current results confirmed this presumption, however showed much higher differences between temperatures measured in the esophagus and urinary bladder, especially during induction of MTH. Thus, a cautious approach is warranted in order not to induce over-cooling when using urinary bladder temperature for hypothermia guidance.

According to available research, the present study has the highest number of systematic, complete (covering three MTH phases: induction, stabilization and warming) comparison of temperature measurements in the esophagus and urinary bladder in comatose patients after cardiac arrest treated with MTH.

\section{Limitations of the study}

The main limitation of this study was a lack of other temperature measurement sites, especially the pulmonary artery, which seems to be the most reliable site for core body temperature measurement.

\section{Conclusions}

The temperature measured in the esophagus remains lower during all three phases of MTH procedure compared with temperature evaluated in the urinary bladder. However, during the stabilization phase most measurements remain within target limits $\left(32-34^{\circ} \mathrm{C}\right)$ regardless of the applied method.

Urinary bladder temperature measurements may lag behind temperature changes measured in the esophagus and time to reach target temperature may be longer when assessing temperature in the urinary bladder.

Monitoring temperature simultaneously in the esophagus and in the urinary bladder is an accessible and reliable combination, although esophageal measurements seem to better reflect the dynamics of temperature changes, thus it seems to be more appropriate for MTH control.

Funding: This study has been developed as part of the "Diamentowy Grant" project financed by the Ministry of Science and Higher Education of the Republic of Poland from research funds for the years 2015-2018 (DI2014 009144).

Conflict of interest: None declared

\section{References}

1. Bernard SA, Gray TW, Buist MD, et al. Treatment of comatose survivors of out-of-hospital cardiac arrest with induced hypothermia. N Engl J Med. 2002; 346(8): 557-563, doi: 10.1056/ /NEJMoa003289, indexed in Pubmed: 11856794.

2. Hypothermia after Cardiac Arrest Study Group. Mild therapeutic hypothermia to improve the neurologic outcome after cardiac arrest. N Engl J Med. 2002; 346(8): 549-556, doi: 10.1056/NEJMoa012689, indexed in Pubmed: 11856793.

3. Dumas F, White L, Stubbs BA, et al. Long-term prognosis following resuscitation from out of hospital cardiac arrest: role of percutaneous coronary intervention and therapeutic hypothermia. J Am Coll Cardiol. 2012; 60(1): 21-27, doi: 10.1016/j. jacc.2012.03.036, indexed in Pubmed: 22742398.

4. Kim YM, Yim HW, Jeong SH, et al. Does therapeutic hypothermia benefit adult cardiac arrest patients presenting with nonshockable initial rhythms?: A systematic review and meta-analysis of randomized and non-randomized studies. Resuscitation. 2012; 83(2): 188-196, doi: 10.1016/j.resuscitation.2011.07.031, indexed in Pubmed: 21835145.

5. Nielsen N, Wetterslev J, Cronberg T, et al. Targeted temperature management at $33^{\circ} \mathrm{C}$ versus $36^{\circ} \mathrm{C}$ after cardiac arrest. N Engl J Med. 2013; 369(23): 2197-2206, doi: 10.1056/nejmoa1310519. 
6. Ibanez B, James S, Agewall S, et al. 2017 ESC Guidelines for the management of acute myocardial infarction in patients presenting with ST-segment elevation: The Task Force for the management of acute myocardial infarction in patients presenting with ST-segment elevation of the European Society of Cardiology (ESC). Eur Heart J. 2018; 39(2): 119-177, doi: 10.1093/eurheartj/ /ehx393, indexed in Pubmed: 28886621.

7. Coppler PJ, Marill KA, Okonkwo DO, et al. Concordance of brain and core temperature in comatose patients after cardiac arrest. Ther Hypothermia Temp Manag. 2016; 6(4): 194-197, doi: 10.1089/ther.2016.0010, indexed in Pubmed: 27249337.

8. Stone JG, Young WL, Smith CR, et al. Do standard monitoring sites reflect true brain temperature when profound hypothermia is rapidly induced and reversed? Anesthesiology. 1995; 82(2): 344-351, indexed in Pubmed: 7856892.

9. Deakin CD, Nolan JP, Soar J, et al. European Resuscitation Council Guidelines for Resuscitation 2010 Section 4. Adult advanced life support. Resuscitation. 2010; 81(10): 1305-1352, doi: 10.1016/j.resuscitation.2010.08.017, indexed in Pubmed: 20956049 .

10. Soar J, Nolan JP, Böttiger BW, et al. European Resuscitation Council Guidelines for Resuscitation 2015: Section 3. Adult advanced nlife support. Resuscitation. 2015; 95: 100-147, doi: 10.1016/j.resuscitation.2015.07.016, indexed in Pubmed: 26477701.

11. Eshel GM, Safar P. Do standard monitoring sites affect true brain temperature when hyperthermia is rapidly induced and reversed. Aviat Space Environ Med. 1999; 70(12): 1193-1196, indexed in Pubmed: 10596773.

12. Camboni D, Philipp A, Schebesch KM, et al. Accuracy of core temperature measurement in deep hypothermic circulatory arrest. Interact Cardiovasc Thorac Surg. 2008; 7(5): 922-924, doi: 10.1510/icvts.2008.181974, indexed in Pubmed: 18658167.

13. Shin J, Kim J, Song K, et al. Core temperature measurement in therapeutic hypothermia according to different phases: com- parison of bladder, rectal, and tympanic versus pulmonary artery methods. Resuscitation. 2013; 84(6): 810-817, doi: 10.1016/j. resuscitation.2012.12.023, indexed in Pubmed: 23306812.

14. Kubica J, Pstragowski K, Adamski P, et al. Mild therapeutic hypothermia for patients with acute coronary syndrome and cardiac arrest treated with percutaneous coronary intervention (UNICORN). The design and rationale for the prospective, observational, multicenter study. Med Res J. 2016; 1(1): 23-27, doi: 10.5603/mrj.2016.0004.

15. Lefrant JY, Muller L, de La Coussaye JE, et al. Temperature measurement in intensive care patients: comparison of urinary bladder, oesophageal, rectal, axillary, and inguinal methods versus pulmonary artery core method. Intensive Care Med. 2003; 29(3): 414-418, doi: 10.1007/s00134-002-1619-5, indexed in Pubmed: 12577157 .

16. Schmitz T, Bair N, Falk M, et al. A comparison of five methods of temperature measurement in febrile intensive care patients. Am J Crit Care. 1995; 4(4): 286-292, indexed in Pubmed: 7663592.

17. Krizanac D, Stratil P, Hoerburger D, et al. Femoro-iliacal artery versus pulmonary artery core temperature measurement during therapeutic hypothermia: an observational study. Resuscitation. 2013; 84(6): 805-809, doi: 10.1016/j.resuscitation.2012.11.022, indexed in Pubmed: 23200998.

18. Erickson RS, Kirklin SK. Comparison of ear-based, bladder, oral, and axillary methods for core temperature measurement. Crit Care Med. 1993; 21(10): 1528-1534, indexed in Pubmed: 8403963.

19. Markota A, Palfy M, Stožer A, et al. Difference between bladder and esophageal temperatures in mild induced hypothermia. J Emerg Med. 2015; 49(1): 98-103, doi: 10.1016/j.jemermed. 2014.12.059, indexed in Pubmed: 25881889.

20. Knapik P, Rychlik W, Duda D, et al. Relationship between blood, nasopharyngeal and urinary bladder temperature during intravascular cooling for therapeutic hypothermia after cardiac arrest. Resuscitation. 2012; 83(2): 208-212, doi: 10.1016/j.resuscitation. 2011.09.001, indexed in Pubmed: 21906572. 